\title{
Multiobjective Electrical Power Dispatch of Thermal Units with Convex and Non-Convex Fuel Cost Functions for 24 Hours Load Demands
}

\author{
Rajanish Kumar Kaushal, Tilak Thakur
}

\begin{abstract}
There are a host of difficult issues with scheduling, operation, and control of integrated power systems. The electricity sector is changing rapidly, and one of the most important concerns is deciding operational strategies to meet electricity demand. It is a greater challenge to satisfy customer demand for power at a minimum cost. The operating characteristics of all generators may be different. In general, operating cost is not proportionate to the performance of these generators. Therefore challenge for power utilities to balance the total load between generators. For a specific load condition on energy systems, Economic Dispatch(ED) seeks to reduce the fuel costs of power generation units. Moreover, energy utilities have also an important task to reduce gaseous emission. So the ED problem can be recognized as a complicated multi-objective optimization problem (MOOP) with two competing targets, the minimal cost of fuel and the minimum emissions effects. This paper presented an efficient method, hybrid of particle swarm optimization (PSO) and a learning-based optimization (TLBO) for combined environmental issues because of gaseous emission and economic dispatch (CEED) problems. The results were shown and verified by PSO and TLBO for standard 3 and 6-generator frameworks with combined issues of emission and economic dispatch taking into account line losses and prohibited zones (POZs) on hourly demand for 24 hours.
\end{abstract}

Keyword: economic, emission, CEED, PSO, TLBO, PSO_TLBO

\section{INTRODUCTION}

Electrical power systems are among the most complicated industrial systems of today's civilization that play a key position in the functioning of contemporary societies. To play this role, electrical power production and distribution must be achieved in an environmentally friendly, cost-effective and reliable manner. The continuing challenge of electrical engineers around the world is to produce, transmit and distribute electricity efficiently. One of the primary goals of the operations and planning project is the lowest possible cost for power demand. The security of individuals and equipment is a more crucial goal. In addition, as a result of the increased number of power plants, minimizing the environmental impact of power generation becomes extremely important.

Revised Manuscript Received on February 15, 2020.

* Correspondence Author

Rajanish Kumar Kaushal*, Pursuing Ph.D. Department of Electrical Engineering, Punjab Engineering College, Chandigarh, India.

Dr. Tilak Thakur, Professor, Department of Electrical Engineering, Punjab Engineering College, Chandigarh, India

(C) The Authors. Published by Blue Eyes Intelligence Engineering and Sciences Publication (BEIESP). This is an open access article under the CC BY-NC-ND license (http://creativecommons.org/licenses/by-nc-nd/4.0/)
The major share of the global electric energy is produced by thermal plants that consume fossil fuels. Heat energy is released from such plants and converted to electricity generation as a mechanical form of energy.

This transformation is carried out via thermal cycles with conversion efficiencies of less than forty percent. It increases the consumption of fuel and decreases the resources that exist. In contrast, the steadily growing worldwide demand for electricity accelerates the depletion of fuel supplies.

Electricity from conventional sources such as oil, natural gas, and coal are the major source of gaseous emissions and contaminants. The question of emission impacts and air pollution in connection with electricity generation has become critical for today's operational procedure in the power system. A large proportion of the total air pollutants and gaseous emissions in the environment are produced from fossil fuel consumption in power generating plants. The negative effects of the various contaminants, including $\mathrm{CO}$ carbon mono oxide, $\mathrm{CO}_{2}$ carbon dioxide, $\mathrm{SO}$ sulphur oxide, $\mathrm{SO}_{2}$ sulphur dioxide NOx nitrogen oxides, Mercury, Cadmium and Lead are of great concern to the public, and cannot be excluded from organizational and preparation approaches. Strict environmental regulations and strong limits on the power generation industry have been implemented globally to minimize this impact on human lives and the atmosphere.

Practically, power losses are estimated to be between 5 percent and 10 percent of the total generation of electricity, Conejo et al. [1] and Wang et al. [2]. The economic dispatch (ED) problem is approached using conventionally designed techniques with a linear differentiable quadratic objective function. The true input-output characteristics include higher nonlinearity and irregularity due to the valve point (VP) effects, which results in non-convex non-linear fuel cost-effectiveness. To show the VP effects a sinusoidal term is added in the conventional fuel cost function, Attavir et al. [3] and Wong et al. [4]. The functions of fuel cost generators are continuously nonlinear and are discontinuous because of prohibited operating zones (POZs). The effect prohibited operating zones is formulated as inequality constraints which are described in Lee et al. [5] and Gaing et al. [6]. Currently the growing concern about the environmental problem due to air pollution Therefore, this research modifies the classical ED problem as CEED to solve the two problems. Two objectives are considered with respect to the CEED problem, namely minimizing fuel costs with a valve loading effect and minimizing emission. 
With minimization of fuel cost and emission, three constraints are also considered during the analysis, namely power balance, capacities limit, and POZs. For dynamic economic emission dispatch , the ramp-rate limit constraint is taken into account together with the above three CEED problem constraints.

Tsay et al. [9] proposed an interactive approach based on Evolutionary programming (EP) to solve CEED problem of cogeneration systems. Kumarappan et al. [10] proposed a back-propagation neural network to solve the optimal economic-emission dispatch for thermal generation systems using cost penalty factor. The paper focused on the only gaseous pollution being nitrogen oxide, as this is the world's main concern.

Venkatesh et al. [11] presented a comparative approach to the issue of the economic dispatch between the EP and two GA-driven approaches. Three algorithms were applied to solve the problem, taking account of the lines flow which was determined using the Newton-Raphson method, while a cost penalty factor was applied to convert the multiobjective in one single function. Chen et al. [12] proposed an approach based integrated neural network to solve the multiobjective CEED problem.

Kumarappan et al. [13] proposed a hybrid method of GA and Tabu search technique to solve the CEED of all-thermal generation system. The objective of the author to combine the two algorithms was to minimize the probability of local minimal trapping and to boost the convergence features of the hybrid algorithm. Kar et al. [14] presented a feed-forward back-propagation neural network to solve the CEED problem. The network was trained using the results of the Lagrangian multiplier technique used initially to resolve the problem.

Brar et al. [15] proposed a Fuzzy set theory to solve CEED problem. A third objective, the security index was regarded as a multi-objective optimization (MOP) problem, as well as cost and emission minimization. Guerrero et al. [16] proposed a Differential Evolution (DE) algorithm Inspired by natural evolution to solve the CEED problem.

King et al. [17] proposed a modified h-factor to solve the CEED problem and the results obtained from PSO to CEED were compare with GA and EP. This h-factor is also known as price penalty factor. The final result shows that PSO was better Than GA and EP for the CEED. Chiang et al. [18] presented an improved GA provided with direction operator and an effective migration operation. A multiplier updating technique was used to prevent the deformation of the augmented Lagrange function. The MOP problem for economic emissions was formulated with the $\varepsilon$-restriction technique to produce optimal Pareto solutions.

Wang et al. [19] proposed a fuzzified multi-objective PSO algorithm to explain the CEED problem. Bharathi et al. [20] presented a comparative study on the application GA and ant colony search algorithms to explain the CEED problem. Prasanna et al. [21] presented a fuzzy mutated EP algorithm to solve the CEED. To prevent premature convergence, fuzzy set theory provides an adaptive scaling factor in the mutation process.

Wang et al. [22] proposed an improved PSO method to deal with the economic load dispatch while simultaneously considering the emission impact. Hemamalini et al. [23] presented a PSO technique to solve CEED problem considering the non-smoothness caused by the valve-point effects of the thermal generating units. Peng et al. [24] presented a DE algorithm based on a Pareto non-dominant sorting technique to solve CEED problem.

Abido et al. [25] presented a modified multi objective PSO to solve CEED optimization problem. The proposed approach provides a multi-objective variant of traditional PSO and uses its usefulness to address problems of multi-objective optimization. Jinchao et al. [26] proposed Rough sets (RS) method and an improved PSO to solve Environmental/economic/reliability Power Dispatch (EERD) problem. Krishna et al. [27] presented an analysis with their highlights, specific features and disadvantages on the current ED optimization techniques for power systems. Moreover, emissions of several pollutants are very harmful in ED techniques, thereby preventing emissions by the research a better technical approach, known as the Combined Economic Emission Dispatch (CEED).

Niknam et al. [28] presented a modified PSO technique for the optimal power flow (OPF) problem. The presented method considers the cost, power loss, and environmental impact, voltage stability as the objective functions. Hooshmand et al. [29] presented a new approach to solve the ED problem. The presented technique considers the spinning reserve and emission costs as the objective functions. Gupta et al. [30] presented PSO method to solve the CEED problem. The price of fuel and emissions are combined with a difference weighting factor in a single function. The main advantage of PSO over other modern heuristics is the simplicity modeling, secure and fast convergence, which gives less computer time than other heuristic methods. Pazheri et al. [31] presented CEED problem with non-convention electrical energy sources and electrical power storage devices. To show the advantages of non-convention sources and energy storage devices and to reduce the emission MATLAB simulations are carried out on IEEE-30 bus data with 6-generators.

Pazheri et al. [32] proposed a multi-objective optimization to solve CEED. The simulation of MATLAB is done using the sequential quadratic algorithm. The analysis showed that renewable energy plants ' electricity costs are smaller than conventional fuel-based plants. ElDesouky et al. [33] provided an optimized dispatch model with security, economics, and environmental considerations. The feasibility of using a PSO method to solve the DEED problem is evaluated using a weighted aggregation technique to achieve a global solution. Krishna et al. [34] presented a Modified Ant Colony Optimization algorithm (MACO) to solve CEED. Chandrasekarana et al., 2014 [35] presented a multi-objective cuckoo search algorithm (CSA) to solve CEED problem. A third objective, the reliability index was regarded as a MOP problem. Khan et al. [36] proposed PSO to solve CEED problem for a system with solar PV plants. Two case studies have been reviewed using PSO as an optimization method with six thermal systems and 13 solar plants. In the first case static CEED problem is solved for maximum and decreased solar radiation and dynamic CEED problem is solved for maximum radiation only with constraints of power generator limits and power balance Nevertheless, in the case of dynamic CEED, the ramp rate limits were considered. 
"Table-I" shows the load characteristics for 24 hours on hourly basis. The maximum demand in 24 hours load is 1150 MW and minimum demand is $650 \mathrm{MW}$. From the table it is seen that load is changing on hourly basis and the load may increase or decrease in next hour. It is better to schedule for 24 hours onetime rather than scheduling of each hour separately for the more optimal economic and emission operation of the thermal units with convex and nonconvex fuel cost functions in power system. Nonconvex fuel cost unit operation is more practical as compare to convex fuel cost unit operation of thermal units in power system.

Load Characteristics:

Table-I: 24 hours hourly basis load demands [8]

\begin{tabular}{lr}
\hline Hour & $\mathrm{P}_{\mathrm{D}}(\mathrm{MW})$ \\
\hline h1 & 750 \\
h2 & 780 \\
h3 & 700 \\
h4 & 650 \\
h5 & 670 \\
h6 & 800 \\
h7 & 950 \\
h8 & 1010 \\
h9 & 1090 \\
h10 & 1080 \\
h11 & 1100 \\
h12 & 1150 \\
h13 & 1110 \\
h14 & 1030 \\
h15 & 1010 \\
h16 & 1060 \\
h17 & 1050 \\
h18 & 1120 \\
h19 & 1070 \\
h20 & 1050 \\
h21 & 910 \\
h22 & 860 \\
h23 & 850 \\
h24 & 800 \\
\hline
\end{tabular}

\section{OPTIMIZATION TECHNIQUES}

\section{(A) Particle Swarm Optimization Technique (Pso):}

Eberhart and Kennedy developed PSO (1995) for the first time and is a population-based optimization algorithm. The population is referred to as "swarm." Each possible solution is known as the particle. Each particle has a random velocity moving randomly in solution space in order to achieve the optimum position. All particles track their former best position in their memory, called best, and corresponding fitness. Pbest's best value is called gbest. Here gbest, is best position that swarm has discovered. If any particle finds a better solution, then all other particles try to move near to that solution. Mathematical equations are the following based on the PSO concept for the search:

Equation to update the velocity of each particle:

$$
v_{i}^{n+1}=\omega^{n} v_{i}^{n}+a_{1} m_{1}\left(\text { pbest }_{i}^{n}-p_{i}^{n}\right)+a_{2} m_{2}\left(\text { gbest }_{i}^{n}-p_{i}^{n}\right)
$$

Equation to update the position of each particle: $p_{i}^{n}=p_{i}^{n+1}+v_{i}^{n}$

Where $v_{i}^{n}, v_{i}^{n+1}$ are the velocities of ith particle at iteration $\mathrm{n}_{\text {th }}$ and $\mathrm{n}^{+} 1_{\mathrm{th}} ;$ pbest $_{i}^{n}$ is ith particle best position at iteration n; $\omega_{i}^{n}$ is weight of inertia at iteration n $g$ best ${ }_{i}^{n}$ is global best position at iteration $n ; p_{i}^{n}$ is the ith particle position at iteration $\mathrm{k} . ; \mathrm{a}_{1}$ and $\mathrm{a}_{2}$ are acceleration coefficients; $\mathrm{m}_{1}$ and $\mathrm{m}_{2}$ are random numbers between $(0,1)$.

Equation to update the inertia weight:

$$
\omega^{n}=\omega_{h}-\frac{\omega_{h}-\omega_{l}}{\text { iter }_{\max }} \times \text { iter }
$$

$\omega_{\mathrm{h}}$ and $\omega_{\mathrm{l}}$ are highest and lowest value of inertia weight and itr $_{\max }$ is maximum iteration number.

\section{(B) Teaching learning optimization (tlbo):}

TLBO algorithm was developed by Rao et al. [31] as an efficient population-based algorithm. The algorithm reflects the instructor's teaching and student's learning capabilities in a classroom. In this process, a population is considered to be a group of students in a class. The best solution so far is similar to the instructor in TLBO since the instructor is regarded as the best-learned person in society. The TLBO system is divided into two phase. The first phase is the "instructor Phase" and the second phase is the "student Phase." The 'instructor phase ' means to learn from the instructor and the 'student phase ' is to learn through interaction. Mean of a class with the $\mathrm{P}$ learner is expressed as:

$$
X_{\text {mean }}=1 / P\left(\sum_{i=1}^{P} X_{i}\right.
$$

Equation to update student's position:

$x_{i, \text { new }}=x_{i, \text { old }}+$ rand.$\left(x_{\text {instructor }}-T_{F} \cdot x_{\text {mean }}\right)$

A student interacts randomly with other students to increase their performance. Student $\mathrm{x}_{\mathrm{i}}$ chooses another student $\mathrm{x}_{\mathrm{j}}$ on a random basis and can express the following equation:

$$
X_{i, n e w}=\left\{\begin{array}{l}
x_{i}^{\text {old }}+\text { rand } .\left(x_{i}-x_{j}\right), \ldots \ldots f\left(x_{i}\right) \leq f\left(x_{j}\right) \\
x_{i}^{\text {old }} \text { _rand } .\left(x_{j}-x_{i}\right), \ldots \ldots f\left(x_{i}\right)>f\left(x_{j}\right)
\end{array}\right.
$$

\section{(C) hybrid pso-tlbo optimization technique:}

The PSO and TLBO principles are used to propose the hybrid PSO_TLBO. Initially generate the population as per problem and calculate the fitness of each population and set the best of pbest as gbest. 
In the next step apply instructor phase and update the population for best fitness. After instructor phase, apply PSO to update pbest and gbest. In the last step apply student phase of TLBO. The hybrid PSO_TLBO improves as compared to the PSO and the TLBO test because population update first in instructor phase then by PSO in last learner phase of TLBO.

\section{CEED PROBLEM DESCRIPTION}

The primary objective of the combined emission economic dispatch of a thermal power system is to minimise the cost as well as reduce the gaseous emission. CEED is a multi-objective problem of emission and economic optimization. The CEED problem can be described as:

$$
\text { Min obj }=\sum_{t=1}^{T} \sum_{i=1}^{N}\left(f_{i t}\left(P_{i t}\right)+E_{i t}\left(P_{i t}\right)\right)
$$

Fuel cost curves are without and with valve point effect are shown in "(8)" and "(9)"

\section{B) Economic Dispatch}

(i) Without valve point effect

$$
f=\sum_{t=1}^{T} \sum_{i=1}^{N} a_{i}+b_{i} P_{i t}+C_{i} P_{i t}^{2}
$$

(ii) With valve point effect

$f=\sum_{t=1}^{T} \sum_{i=1}^{N} a_{i}+b_{i} P_{i t}+c_{i} P_{i t}^{2}+\left|e_{i}^{*} \sin \left(f_{i}^{*}\left(P_{i}^{\min }-P_{i t}\right)\right)\right| \$ / h$

Where:

$a_{i}, b_{i}, c_{i}$ ei, fi : $i_{\text {th }}$ generating unit fuel cost coefficients . $\mathrm{Pi}^{\mathrm{min}}=$ minimum generated power by the unit ith Pit: generated power by the $i_{\text {th }}$ unit in scheduled period $t$.

$\mathrm{N}$ : total number of thermal units.

$\mathrm{T}=$ total time

B) Emission Dispatch

$E=\sum_{t=1}^{T} \sum_{i=1}^{N}\left(\alpha_{i}{ }^{+} \beta_{i} P_{i t}+\gamma_{i} P_{i t}^{2}+n_{i} \exp \left(\delta_{i} P_{i t}\right)\right) k g / h$

$\alpha_{i}, \beta i, \gamma_{i}, \eta_{i}, \delta_{i}$ are ith thermal unit's emission coefficients

Linear and non-Linear Constraints:

C) Power balance limit

$$
\sum_{i=1}^{N} P_{i t}-P_{D t}-P_{L i t}=0
$$

$\mathrm{P}_{\mathrm{Lt}}$ :line losses in scheduled period $\mathrm{t}$

$\mathrm{P}_{\mathrm{Dt}}$ : Demand in schedule period $\mathrm{t}$

\section{D) Generation limits}

$$
P_{i}^{\min } \leq P_{i t} \leq P_{i}^{\max }
$$

$\mathrm{P}_{\mathrm{i}}{ }^{\mathrm{min}}$ : minimum power loading limit of ith unit $\mathrm{P}_{\mathrm{i}}^{\text {max }}$ : maximum power loading limit by ith unit.

\section{E) Prohibited zones Limits}

As follows, the operating zones of ith can be described:

$$
\begin{gathered}
P_{i}^{\text {min }} \leq P_{i} \leq P_{i, 1}^{\text {lower }} \\
P_{i, k-1}^{\text {upper }} \leq P_{i} \leq P_{i, k}^{\text {lower }} k=2,3, \ldots . . n_{i} \\
P_{i, n_{i}}^{\text {upper }} \leq P_{i} \leq P_{i}^{\max }
\end{gathered}
$$

Where:

$\mathrm{n}_{\mathrm{j}}$ : Total zones of ith generation unit prohibited;

$P_{i, k}^{\text {lower }}$ : Lower limit of prohibited zone of $\mathrm{k}$ of ith unit, $P_{i, k-1}^{\text {upper }}$ : Upper limit of prohibited zone of k-1 of ith unit.

With the introduction of the " $h$ " cost penalty factor, the MOP function of "(7)" can be translated into a single-objective optimization problem.

Min $o b j=\sum_{t=1}^{T} \sum_{i=1}^{N}\left(f_{i t}\left(P_{i t}\right)+h_{i} E_{i t}\left(P_{i t}\right)\right)$

For convex system:

$$
h_{i}=\frac{a_{i}+b_{i} P_{i t}+c_{i} P_{i t}^{2}}{\left(\alpha_{i}+\beta_{i} P_{i t}+\gamma_{i} P_{i t}^{2}+n_{i} \exp \left(\delta_{i} P_{i t}\right)\right)}
$$

For non-convex system:

$$
h_{i}=\frac{a_{i}+b_{i} P_{i t}+c_{i} P_{i t}^{2}+\left|e_{i}^{*} \sin \left(f_{i}^{*}\left(P_{i}^{\min }-P_{i t}\right)\right)\right| \$ / h}{\left(\alpha_{i}+\beta_{i} P_{i t}+\gamma_{i} P_{i t}^{2}+n_{i} \exp \left(\delta_{i} P_{i t}\right)\right)}
$$

Table-II: Cost coefficients and generation limits for 3-units

\begin{tabular}{llll}
\hline Parameters & UNIT-1 & UNIT-2 & UNIT-3 \\
\hline $\mathrm{a}_{\mathrm{i}}$ & 100 & 120 & 150 \\
$\mathrm{~b}_{\mathrm{i}}$ & 2.45 & 2.32 & 2.10 \\
$\mathrm{C}_{\mathrm{i}}$ & 0.0012 & 0.0010 & 0.0015 \\
$\mathrm{e}_{\mathrm{i}}$ & 160 & 180 & 200 \\
$\mathrm{f}_{\mathrm{i}}$ & 0.038 & 0.037 & 0.035 \\
$\mathrm{Pi}^{\text {min }}$ & 20 & 40 & 50 \\
$\mathrm{Pi}^{\text {max }}$ & 500 & 500 & 500 \\
\hline
\end{tabular}

Table-III: Emission coefficients for 3-units [8]

\begin{tabular}{lcll}
\hline Parameters & UNIT- 1 & UNIT-2 & UNIT-3 \\
\hline$\alpha_{\mathrm{i}}$ & 0.0105 & 0.0080 & 0.0120 \\
$\beta_{\mathrm{i}}$ & -1.355 & -0.600 & -0.555 \\
$\gamma_{\mathrm{i}}$ & 60 & 45 & 30 \\
$\eta$ & 0.4968 & 0.4860 & 0.5035 \\
$\delta$ & 0.01925 & 0.01694 & 0.01478 \\
\hline
\end{tabular}


"(11)" to "(13)" represents the linear and non linear constraints for CEED operation and "(14)" represents the final objective for CEED operation and "(15)" and "(16)"to calculate price penalty factor.

Table-IV: Cost coefficients and power limits for 6-units [6]

\begin{tabular}{c|c|c|c|c|c}
\hline Unit & $\begin{array}{c}\mathrm{C}_{\mathrm{i}} \\
\left(\$ / \mathrm{MW}^{2}\right)\end{array}$ & $\begin{array}{c}\mathrm{b}_{\mathrm{i}} \\
(\$ / \mathrm{MW})\end{array}$ & $\begin{array}{c}\mathrm{a}_{\mathrm{i}} \\
(\$)\end{array}$ & $\begin{array}{c}\mathrm{P}_{\mathrm{i}}{ }^{\max } \\
(\mathrm{MW})\end{array}$ & $\begin{array}{c}\mathrm{P}_{\mathrm{i}}{ }^{\min } \\
(\mathrm{MW})\end{array}$ \\
\hline 1 & 0.0070 & 7.0 & 240 & 500 & 100 \\
2 & 0.0095 & 10.0 & 200 & 200 & 50 \\
3 & 0.0090 & 8.5 & 220 & 300 & 80 \\
4 & 0.0090 & 11.0 & 200 & 150 & 50 \\
5 & 0.0080 & 10.5 & 220 & 200 & 50 \\
6 & 0.0075 & 12.0 & 190 & 120 & 50 \\
\hline
\end{tabular}

Table -V: Emission coefficients for 6-units [6]

\begin{tabular}{c|l|c|l}
\hline Units & $\alpha(\mathrm{lb} / \mathrm{h})$ & $\beta(\mathrm{lb} / \mathrm{MW} / \mathrm{h})$ & $\gamma\left(\mathrm{lb} / \mathrm{MW}^{2} / \mathrm{h}\right)$ \\
\hline 1 & 13.85932 & 0.32767 & 0.00419 \\
2 & 13.85932 & 0.32767 & 0.00419 \\
3 & 40.26690 & -0.54551 & 0.00683 \\
4 & 40.26690 & -0.54551 & 0.00683 \\
5 & 42.89553 & -0.51116 & 0.00461 \\
6 & 42.89553 & -0.51116 & 0.00461 \\
\hline
\end{tabular}

Table-VI: Prohibited zones for 6-units [6]

\begin{tabular}{|c|c|c|c|c|}
\hline Unit & $\begin{array}{l}\text { Prohibited zones } \\
\text { MW) }\end{array}$ & $\mathrm{P}_{\mathrm{i}}^{0}$ & $\mathrm{UPR}_{\mathrm{i}}$ & $\mathrm{DPR}_{\mathrm{i}}$ \\
\hline 1 & {$\left[\begin{array}{lll}210 & 240][350 & 380\end{array}\right]$} & 440 & 80 & 120 \\
\hline 2 & {$\left[\begin{array}{ll}90 & 110]\left[\begin{array}{ll}140 & 160\end{array}\right]\end{array}\right.$} & 170 & 50 & 90 \\
\hline 3 & {$\left[\begin{array}{ll}150 & 170][210\end{array}\right.$} & 200 & 65 & 100 \\
\hline 4 & {$\left[\begin{array}{ll}80 & 90\end{array}\right]\left[\begin{array}{ll}110 & 120\end{array}\right]$} & 150 & 50 & 90 \\
\hline 5 & 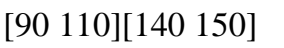 & 190 & 50 & 90 \\
\hline 6 & [75 85][100 105] & 110 & 50 & 90 \\
\hline
\end{tabular}

\section{RESULTS AND DISCUSSION}

The proposed algorithm is applied on 3-units and 6-units of thermal plants for CEED problem. There cases are considered here first case for three units with valve point effects and transmission losses and second case for 6 units with line losses and third case for 6 units with prohibited zone as an additional constraint in second case. MATLAB simulation is performed on MATLAB R2010a with Intel's earlier Core Duo processor, 1.6 GHz with 3GB RAM.

Case-I: The test system-I compromised 3-thermal units with valve point effect and transmission losses. PSO parameters a1, a2=2, swarm size $=50$, and maximum iteration $=500$, minimum and maximum velocity are $-0.5 * \mathrm{Pmin}$ and $0.5 *$ Pmax and for TLBO; swarm size $=50$ and maximum iteration $=500$ are used for all cases. Cost coefficients, power limits is taken from "Table-II" and emission coefficient is taken from "Table-III" and loss matrix is taken from [7].

Table-VII: Comparison Result for case-I

\begin{tabular}{c|c|c|c}
\hline TERMS & PSO & TLBO & PSO_TLBO \\
\hline TC & 128357.7 & 128140.3 & $\mathbf{1 1 6 5 8 3 . 7}$ \\
TFC & 83155.5 & 83001.8 & $\mathbf{7 5 4 2 7 . 3}$
\end{tabular}

Table -IX: hourly fuel cost, emission, losses for case-I

\begin{tabular}{c|c|c|c}
\hline Hour & $\begin{array}{c}\text { Fuel cost } \\
\text { (\$/h) }\end{array}$ & $\begin{array}{c}\text { Emission } \\
\text { (Kg/h) }\end{array}$ & $\begin{array}{c}\text { Loss } \\
\text { (MW) }\end{array}$ \\
\hline h1 & 2543.1 & 1799.3 & 14.3 \\
h2 & 2471.5 & 1900.3 & 11.5 \\
h3 & 2522.6 & 2092.2 & 14.1 \\
h4 & 2210.7 & 2645.1 & 8.0 \\
h5 & 2401.4 & 2342.0 & 13.0 \\
h6 & 2656.3 & 1892.7 & 12.6 \\
h7 & 3127.3 & 3485.2 & 17.5 \\
h8 & 3223.6 & 4128.3 & 18.5 \\
h9 & 3599.3 & 4972.4 & 22.3 \\
h10 & 3482.7 & 5538.0 & 23.9 \\
h11 & 3567.1 & 4895.9 & 24.7 \\
h12 & 3743.7 & 5111.2 & 26.1 \\
h13 & 3526.5 & 4530.0 & 24.4 \\
h14 & 3480.2 & 6272.9 & 22.1 \\
h15 & 3319.2 & 3433.9 & 21.0 \\
h16 & 3428.6 & 4601.8 & 25.6 \\
h17 & 3471.7 & 4056.3 & 24.0 \\
h18 & 3696.6 & 4705.4 & 25.7 \\
h19 & 3701.1 & 4673.6 & 24.1 \\
h20 & 3560.8 & 7525.6 & 30.7 \\
h21 & 3137.1 & 2885.1 & 15.7 \\
h22 & 2697.9 & 2245.4 & 14.6 \\
h23 & 2795.3 & 2481.8 & 13.3 \\
h24 & 2650.3 & 1922.5 & 12.5 \\
\hline & & & \\
\hline
\end{tabular}

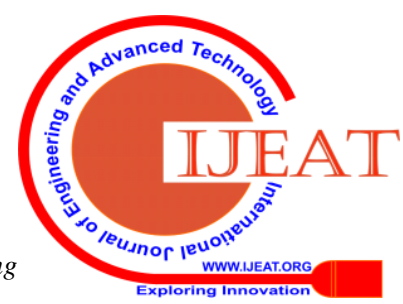


Multiobjective Electrical Power Dispatch of Thermal Units with Convex and Non-Convex Fuel Cost Functions for 24 Hours Load Demands

Table-"VI" shows the result obtained from the proposed method and it compares from other methods PSO and TLBO for case-I and "Table-VII" show the optimal hourly power generation from all the three committed units and "Table-VIII" shows the hourly fuel cost, emission, and losses.

Case-II: The test system-I compromised 6-thermal units for CEED with transmission losses. Cost coefficient, power limit data is taken from "table-IV", emission coefficients are taken from "table $-\mathrm{V}$ " and loss matrix is taken from [6].

Table -X: hourly power generated (P1-P3) for case-II

\begin{tabular}{c|c|c|c}
\hline $\begin{array}{l}\text { Hou } \\
\text { r }\end{array}$ & $\begin{array}{c}\text { P1 } \\
\text { (MW) }\end{array}$ & $\begin{array}{c}\text { P2 } \\
\text { (MW) }\end{array}$ & $\begin{array}{c}\text { P3 } \\
\text { (MW) }\end{array}$ \\
\hline h1 & 203.5 & 119.7 & 117.5 \\
h2 & 211.6 & 122.7 & 119.8 \\
h3 & 192.8 & 111.1 & 108.4 \\
h4 & 183.6 & 101.1 & 98.4 \\
h5 & 186.3 & 105.3 & 101.9 \\
h6 & 209.2 & 128.7 & 120.2 \\
h7 & 246.3 & 159.2 & 145.9 \\
h8 & 268.2 & 173.6 & 160.5 \\
h9 & 296.6 & 194.5 & 179.3 \\
h10 & 293.3 & 193.1 & 177.3 \\
h11 & 301.9 & 196.9 & 180.9 \\
h12 & 322.4 & 200.0 & 197.5 \\
h13 & 304.3 & 199.9 & 185.4 \\
h14 & 275.8 & 179.5 & 164.6 \\
h15 & 269.7 & 173.4 & 160.3 \\
h16 & 285.9 & 187.4 & 172.2 \\
h17 & 283.0 & 184.6 & 169.5 \\
h18 & 308.7 & 200.0 & 187.6 \\
h19 & 290.4 & 189.4 & 174.6 \\
h20 & 281.7 & 184.8 & 171.0 \\
h21 & 238.8 & 150.2 & 141.6 \\
h22 & 227.3 & 139.4 & 131.2 \\
h23 & 222.9 & 138.2 & 130.3 \\
h24 & 208.9 & 127.9 & 120.6 \\
\hline & & & \\
\hline
\end{tabular}

Table -XI: hourly power generated (P4-P6) for case-II

\begin{tabular}{c|c|c|c}
\hline $\begin{array}{c}\text { Ho } \\
\text { ur }\end{array}$ & $\begin{array}{c}\text { P4 } \\
\text { (MW) }\end{array}$ & $\begin{array}{c}\text { P5 } \\
\text { (MW) }\end{array}$ & $\begin{array}{c}\text { P6 } \\
\text { (MW) }\end{array}$ \\
\hline h1 & 63.3 & 142.2 & 109.5 \\
h2 & 66.9 & 152.2 & 112.9 \\
h3 & 57.5 & 136.5 & 98.6 \\
h4 & 52.8 & 128.9 & 89.5 \\
h5 & 55.2 & 131.3 & 94.6 \\
h6 & 68.8 & 159.8 & 120.0 \\
h7 & 87.7 & 200.0 & 120.0 \\
h8 & 97.4 & 200.0 & 120.0 \\
h9 & 110.2 & 200.0 & 120.0 \\
h10 & 106.8 & 200.0 & 120.0 \\
h11 & 111.0 & 200.0 & 120.0 \\
h12 & 121.4 & 200.0 & 120.0 \\
h13 & 111.3 & 200.0 & 120.0 \\
h14 & 100.0 & 200.0 & 120.0 \\
h15 & 96.3 & 200.0 & 120.0 \\
h16 & 104.7 & 200.0 & 120.0 \\
h17 & 103.0 & 200.0 & 120.0 \\
h18 & 114.7 & 200.0 & 120.0 \\
h19 & 105.9 & 200.0 & 120.0 \\
h20 & 102.6 & 200.0 & 120.0 \\
h21 & 81.7 & 186.0 & 120.0 \\
h22 & 75.4 & 174.3 & 120.0
\end{tabular}

\begin{tabular}{llll}
$\mathbf{h} 23$ & 74.0 & 172.1 & 120.0 \\
$\mathbf{h} 24$ & 69.3 & 160.1 & 120.0 \\
\hline
\end{tabular}

Table -XII: hourly fuel cost, emission, losses for case-II

\begin{tabular}{c|c|c|c}
\hline $\begin{array}{c}\text { Ho } \\
\mathbf{u r}\end{array}$ & $\begin{array}{c}\text { Fuel Cost } \\
\mathbf{( \$ / h )}\end{array}$ & $\begin{array}{c}\text { Emission } \\
\mathbf{( k g} / \mathbf{h})\end{array}$ & $\begin{array}{c}\text { Loss } \\
\mathbf{( M W )}\end{array}$ \\
\hline $\mathbf{h 1}$ & 9230.7 & 580.4 & 5.6 \\
$\mathbf{h 2}$ & 9592.7 & 668.0 & 6.2 \\
$\mathbf{h} 3$ & 8636.1 & 444.5 & 4.9 \\
$\mathbf{h} 4$ & 8048.9 & 325.3 & 4.3 \\
$\mathbf{h} 5$ & 8287.8 & 368.9 & 4.5 \\
$\mathbf{h 6}$ & 9865.8 & 719.7 & 6.6 \\
$\mathbf{h 7}$ & 11685.2 & 1297.6 & 9.1 \\
$\mathbf{h 8}$ & 12394.0 & 1589.1 & 9.7 \\
$\mathbf{h 9}$ & 13369.0 & 2032.5 & 10.6 \\
$\mathbf{h 1 0}$ & 13245.7 & 1973.5 & 10.5 \\
$\mathbf{h 1 1}$ & 13490.9 & 2092.6 & 10.7 \\
$\mathbf{h 1 2}$ & 14100.5 & 2412.6 & 11.3 \\
$\mathbf{h 1 3}$ & 13615.4 & 2153.5 & 10.9 \\
$\mathbf{h 1 4}$ & 12635.3 & 1693.9 & 9.9 \\
$\mathbf{h 1 5}$ & 12391.5 & 1589.7 & 9.7 \\
$\mathbf{h 1 6}$ & 13000.5 & 1858.6 & 10.2 \\
$\mathbf{h 1 7}$ & 12877.6 & 1802.9 & 10.1 \\
$\mathbf{h 1 8}$ & 13736.9 & 2216.1 & 11.0 \\
$\mathbf{h 1 9}$ & 13121.0 & 1915.9 & 10.4 \\
$\mathbf{h 2 0}$ & 12878.3 & 1802.8 & 10.1 \\
$\mathbf{h 2 1}$ & 11177.9 & 1129.9 & 8.3 \\
$\mathbf{h 2 2}$ & 10572.7 & 932.9 & 7.5 \\
$\mathbf{h 2 3}$ & 10455.9 & 895.0 & 7.4 \\
$\mathbf{h 2 4}$ & 9866.2 & 719.6 & 6.7 \\
\hline
\end{tabular}

Table-XIII: Comparison Result for case-II

\begin{tabular}{c|c|c|c}
\hline $\begin{array}{c}\text { TERM } \\
\text { S }\end{array}$ & PSO & TLBO & PSO_TLBO \\
\hline TC & 517781.4 & 517741.5 & $\mathbf{4 7 8 1 4 5 . 4}$ \\
TFC & 311044.2 & 31146.9 & $\mathbf{2 7 8 2 7 6 . 4}$ \\
TE & 44437.1 & 44430.3 & $\mathbf{3 3 2 1 5 . 3 9}$ \\
TL & 245.3 & 245.3 & $\mathbf{2 0 6 . 2 3 9 8}$ \\
\hline
\end{tabular}

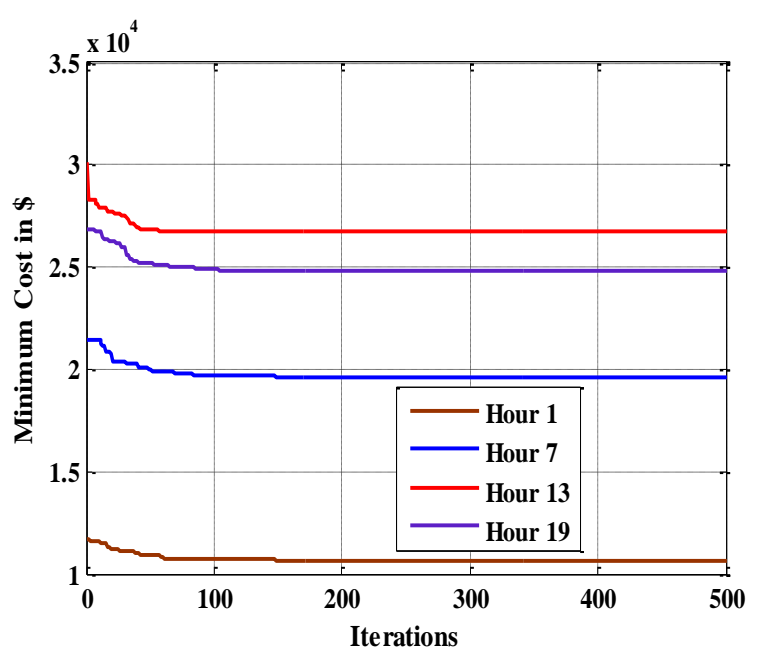

Fig.1: hourly cost variations for case-II

Published By:

Blue Eyes Intelligence Engineering 
Case-III: The case-III compromised 6-thermal units for CEED with transmission losses and an additional constraint prohibited zones. Cost coefficient, power limit data is taken from "table-IV", emission coefficients are taken from "table $-\mathrm{V}$ ", prohibited zone data is taken from "table-VI", and loss matrix is taken from [6] for combined economic emission dispatch of power system for 24 hours hourly load demands.

Table-XIV: hourly power generated (P1-P3) for case-III

\begin{tabular}{|c|c|c|c|}
\hline $\begin{array}{l}\text { Hou } \\
\text { r }\end{array}$ & $\begin{array}{c}\text { P1 } \\
\text { (MW) }\end{array}$ & $\begin{array}{c}\mathbf{P} 2 \\
(\mathbf{M W})\end{array}$ & $\begin{array}{c}\text { P3 } \\
\text { (MW) }\end{array}$ \\
\hline h1 & 190.3 & 89.9 & 170.0 \\
\hline h2 & 240.0 & 114.4 & 111.3 \\
\hline h3 & 168.8 & 110.1 & 96.4 \\
\hline h4 & 162.0 & 88.7 & 170.0 \\
\hline h5 & 183.8 & 110.4 & 100.2 \\
\hline h6 & 177.1 & 110.4 & 170.0 \\
\hline h7 & 240.0 & 160.0 & 131.2 \\
\hline h8 & 240.9 & 139.8 & 240.0 \\
\hline h9 & 270.7 & 172.4 & 240.1 \\
\hline h10 & 380.0 & 136.4 & 170.1 \\
\hline h11 & 380.0 & 139.9 & 170.0 \\
\hline h12 & 381.3 & 140.0 & 242.6 \\
\hline h13 & 380.0 & 160.0 & 170.0 \\
\hline h14 & 268.7 & 189.7 & 174.4 \\
\hline h15 & 319.6 & 140.0 & 190.7 \\
\hline h16 & 282.5 & 182.8 & 176.9 \\
\hline h17 & 298.9 & 140.0 & 181.0 \\
\hline h18 & 380.0 & 160.5 & 240.0 \\
\hline h19 & 284.4 & 174.8 & 240.0 \\
\hline h20 & 380.0 & 128.8 & 170.0 \\
\hline h21 & 240.2 & 160.2 & 135.9 \\
\hline h22 & 240.1 & 137.8 & 126.1 \\
\hline h23 & 200.7 & 160.0 & 170.0 \\
\hline h24 & 240.0 & 90.0 & 170.0 \\
\hline
\end{tabular}

Table -XV: hourly power generated (P4-P6) for case-III

\begin{tabular}{|c|c|c|c|}
\hline $\begin{array}{l}\text { Ho } \\
\text { ur }\end{array}$ & $\begin{array}{c}\text { P4 } \\
\text { (MW) }\end{array}$ & $\begin{array}{c}\text { P5 } \\
\text { (MW) }\end{array}$ & $\begin{array}{l}\text { P6 } \\
\text { (MW) }\end{array}$ \\
\hline h1 & 56.8 & 150.2 & 98.5 \\
\hline h2 & 60.8 & 139.6 & 120.0 \\
\hline h3 & 90.0 & 150.2 & 89.4 \\
\hline h4 & 50.0 & 110.1 & 73.1 \\
\hline h5 & 53.8 & 132.7 & 93.7 \\
\hline h6 & 120.0 & 129.4 & 98.4 \\
\hline h7 & 120.0 & 187.1 & 120.0 \\
\hline h8 & 90.2 & 188.8 & 120.0 \\
\hline h9 & 97.7 & 200.0 & 120.0 \\
\hline h10 & 120.0 & 183.2 & 100.0 \\
\hline h11 & 120.0 & 180.3 & 120.0 \\
\hline h12 & 136.4 & 140.0 & 120.0 \\
\hline h13 & 120.1 & 170.1 & 120.0 \\
\hline h14 & 107.1 & 200.0 & 99.6 \\
\hline h15 & 108.6 & 139.4 & 120.0 \\
\hline h16 & 108.0 & 200.0 & 120.0 \\
\hline h17 & 120.1 & 200.0 & 120.0 \\
\hline h18 & 90.0 & 185.4 & 74.9 \\
\hline h19 & 120.0 & 140.0 & 120.0 \\
\hline h20 & 120.0 & 140.0 & 120.0 \\
\hline h21 & 78.2 & 183.7 & 120.0 \\
\hline h22 & 90.0 & 172.9 & 99.9 \\
\hline h23 & 66.1 & 140.0 & 120.0 \\
\hline h24 & 66.5 & 139.7 & 99.7 \\
\hline
\end{tabular}

Table -XVI: hourly fuel cost, emission, losses for case-III

\begin{tabular}{|c|c|c|c|}
\hline $\begin{array}{c}\text { Ho } \\
\text { ur }\end{array}$ & $\begin{array}{c}\text { Fuel Cost } \\
(\$ / h)\end{array}$ & $\begin{array}{l}\text { Emission } \\
(\mathrm{Kg} / \mathrm{h})\end{array}$ & $\begin{array}{l}\text { Loss } \\
(\mathrm{MW})\end{array}$ \\
\hline h1 & 9203.314 & 687.8801 & 5.751541 \\
\hline h2 & 9550.918 & 705.3528 & 6.108772 \\
\hline h3 & 8722.851 & 466.206 & 4.851054 \\
\hline h4 & 7997.621 & 487.0264 & 3.915377 \\
\hline h5 & 8296.788 & 366.3001 & 4.555292 \\
\hline h6 & 9849.34 & 927.3376 & 5.27226 \\
\hline h7 & 11709.87 & 1338.688 & 8.38619 \\
\hline h8 & 12384.97 & 1775.179 & 9.640767 \\
\hline h9 & 13371.97 & 2136.322 & 10.86735 \\
\hline h10 & 13105.18 & 2269.818 & 9.754574 \\
\hline h11 & 13381.85 & 2312.531 & 10.21301 \\
\hline h12 & 13977.08 & 2839.215 & 10.27339 \\
\hline h13 & 13504.78 & 2358.995 & 10.14364 \\
\hline h14 & 12622.73 & 1760.386 & 9.536969 \\
\hline h15 & 12225.06 & 1809.065 & 8.331443 \\
\hline h16 & 12997.88 & 1860.619 & 10.2026 \\
\hline h17 & 12825.76 & 1869.872 & 9.962864 \\
\hline h18 & 13575 & 2657.709 & 10.84919 \\
\hline h19 & 13047.55 & 2172.515 & 9.161305 \\
\hline h20 & 12716.11 & 2166.847 & 8.816639 \\
\hline h21 & 11185.45 & 1131.371 & 8.281045 \\
\hline h22 & 10521.3 & 978.5978 & 7.000244 \\
\hline h23 & 10446.21 & 975.3923 & 6.784486 \\
\hline h24 & 9700.952 & 886.201 & 5.936419 \\
\hline
\end{tabular}

Table-XVII: Comparison Result for case-III

\begin{tabular}{c|c|r|c}
\hline TERMS & PSO & TLBO & PSO_TLBO \\
\hline TC & 546576.7 & 534948.8 & $\mathbf{5 0 0 0 2 0 . 1}$ \\
TFC & 320765.4 & 310879.5 & $\mathbf{2 7 6 9 2 0 . 6}$ \\
TE & 48814.3 & 46817.19 & $\mathbf{3 6 9 3 9 . 4 3}$ \\
TL & 256.6 & 239.8915 & $\mathbf{1 9 4 . 5 9 6 4}$
\end{tabular}

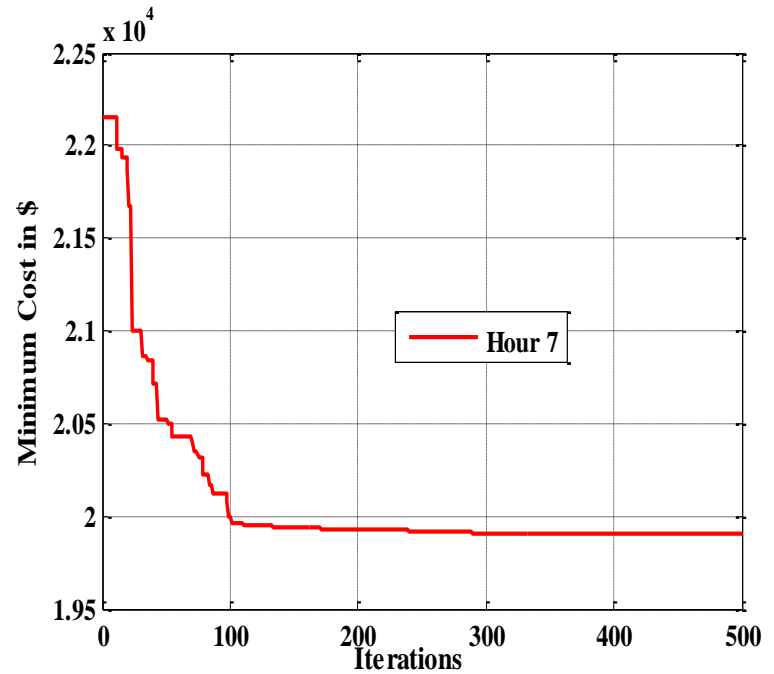

Fig.2: Variation of cost in hour-7 for case-III 
Table-"XIII" shows the result obtained from the proposed method and it compares from other methods PSO and TLBO for case-II and "Table-X" show the optimal hourly power generation from three committed units (P1-P3) and "Table-XI" show the optimal hourly power generation from three committed units (P4-P6) and "Table-XII" shows the hourly fuel cost, emission, and losses for case-II. Table-"XVII" shows the result obtained from the proposed method and it compares from other methods PSO and TLBO for case-III "Table-XIV" show the optimal hourly power generation from three committed units (P1-P3) and "Table-XV" show the optimal hourly power generation from three committed units (P4-P6) and "Table-XVI" shows the hourly fuel cost, emission, and losses for case-III.

\section{CONCLUSION}

The paper shows an efficient and effective method based on a hybrid of PSO and TLBO for CEED problems. Three cases are considered in this paper. In the first case, three thermal units with valve point effect and line losses are considered and solved for CEED with the proposed method PSO_TLBO and result obtained from the proposed method are also verified and analysis with the PSO and TLBO methods. In the second case, six thermal units with transmission line losses are considered and solve for CEED with proposed methods. For the third case, an additional constraint prohibited zone is considered in the second case. Results obtained from the second and third cases are also verified and compared with PSO and TLBO methods as the case first. In all the cases proposed method gives better results as compare to PSO and TLBO methods but conversion time is much more as compare to PSO and TLBO methods.

\section{REFERENCES}

1. J. Conejo, S. Member, F. D. Galiana, and I. Kockar, "Z -Bus Loss Allocation,” IEEE Trans. Power Syst., vol. 16, no. 1, pp. 105-110, Feb. 2001.

2. H. X. Wang, R. Liu, and W. D. Li, "Transmission loss allocation based on circuit theories and orthogonal projection," IEEE Trans. Power Syst., vol. 24, no. 2, pp. 868-877, May 2009.

3. P. Attaviriyanupap, H. Kita, E. Tanaka, and J. Hasegawa, "A hybrid EP and SQP for dynamic economic dispatch with nonsmooth fuel cost function," IEEE Trans. Power Syst., vol. 17, no. 2, pp. 411-416, May 2002.

4. K.P. Wong and Y.W. Wong, "Genetic and genetic/simulated-annealing approaches to economic dispatch," in Proc. Inst. Electr. Eng., Gen., Transm. Distrib. vol. 141, pp. 507-513, Sep. 1994

5. F.N. Lee and A.M. Breipohl, "Reserve constrained economic dispatch with prohibited operating zones," IEEE Trans. Power Syst., vol. 8, no. 1, pp. 246-254, Feb. 1996.

6. Z. L. Gaing, "Particle swarm optimization to solving the economic dispatch considering the generator constraints," IEEE Trans. Power Syst., vol. 18, no. 3, pp. 1187-1195, Aug. 2003.

7. M.F. AlHajri and M.E. El-Hawary, "Pattern search optimization applied to convex and non-convex economic dispatch, Systems," Man and Cybernetics, 2007. ISIC. IEEE Inter. Conf., pp. 2674-2678, 2007.

8. M.Basu, "An interactive fuzzy satisfying method based on evolutionary programming technique for multiobjective short-term hydrothermal scheduling, "Electr. Power Syst. Res., vol.69, pp. 277-285, 2004.

9. M.-. Tsay, W.-. Lin, and J.-. Lee, "Interactive best-compromise approach for operation dispatch of cogeneration systems," in Proc. Inst. Electr. Eng., Gen., Transm. Distrib. vol. 148, no.4, pp. 326-332, Jul. 2001.

10. N. Kumarappan, M.R. Mohan, and S. Murugappan, "ANN approach system," in Proc. Int. Joint Conf. on Neural Networks IJCNN '02, 2002, vol. 1,no.3, pp. 323-327.

11. P. Venkatesh, R. Gnanadass, and N.P. Padhy, "Comparison and application of evolutionary programming techniques to combined applied to combined economic and emission dispatch for large-scale

economic emission dispatch with line flow constraints," IEEE Trans. Power Syst, vol. 18, no.2, pp. 688-697, May 2003.

12. P. C Chen and C.M. Huang, "Biobjective power dispatch using goal-attainment method and adaptive polynomial networks," IEEE Trans. Energy Convers., vol. 19, no.4, pp. 741-747, Dec. 2004.

13. N. Kumarappan and M.R. Mohan, "Hybrid genetic algorithm based combined economic and emission dispatch for utility system," in Proc. of Int. Conf. on Intelligent Sensing and Inf. Processing, 2004, pp. 19-24.

14. Kar, K.K. Mandal, D. Pal, and N. Chakraborty, "Combined economic and emission dispatch by ANN with backprop algorithm using variant learning rate \& momentum coefficient," in proc. 7th Int. Conf. on Power Eng., 2005,pp. 1-6.

15. Y.S. Brar, J.S. Dhillon, and D.P. Kothari, "Fuzzy satisfying multi-objective generation scheduling based on simplex weight age pattern search,” Int. J. of Electr. Power \& Energy Syst., vol. 27, pp. 518-527, 2005.

16. R.E. Perez-Guerrero and J.R. Cedeno-Maldonado, "Differential evolution based economic environmental power dispatch," in Proc 37th Annual North American, Power Symposium,2005, pp.191-197, 2005.

17. R.T.F. King, H.C.S. Rughooputh, and K. Deb, "Stochastic Evolutionary Multiobjective Environmental/Economic Dispatch," in proc. IEEE Evolu. Compu. On Cong. (CEC), Canada, Jul. 16-21, 2006, pp. 946-953.

18. C.L. Chiang and C.W. Chai, "A Multi-Objective Optimization for Power Economic Dispatch," in proc. IEEE Int. Conf. on Systems, Man and Cybernetics,. SMC '06, Taiwan, Oct 8-11, 2006, vol. 2, pp. 1587-1591.

19. L. Wang and C. Singh, "Environmental/economic power dispatch using a fuzzified multi-objective particle swarm optimization algorithm," Electr. Power Syst. Res., pp.1656-1664, 2007.

20. R. Bharathi, M.J. Kumar, D. Sunitha, and S. Premalatha, "Optimization of combined economic and emission dispatch problem - A comparative study," in proc. Int. Conf. Power Eng. -IPEC, 2007, pp. 134-139, 2007.

21. T.S. Prasanna and P. Somasundaram, "Fuzzy mutated evolutionary programming based algorithm for combined economic and emission dispatch," in proc. $10^{\text {th }}$ IEEE Region Conf., 2008, pp. 1-5.

22. L. Wang and C. Singh, "Stochastic economic emission load dispatch through a Modified particle Swarm optimization algorithm," Electr. Power Syst. Res., pp.1466-1476, 2008.

23. S. Hemamalini and S.P. Simon, "Emission constrained economic dispatch with valve-point effect using particle swarm optimization," in proc. IEEE Region $10^{\text {th }}$ Conf., TENCON, 2008, pp. 1-6.

a. Peng, H. Sun, J. Guo, and H. Li, "A new algorithm based on non-dominated sorting differential evolution for multi-objective optimal load dispatch," in proc. 2nd IEEE Int. Conf. on Comp. Sci. and Inf. Tech. (ICCSIT'09),2009, pp. 565-569.

24. M.A. Abido, "Multiobjective particle swarm optimization for environmental/economic dispatch problem, " Electr. Power Syst. Res., pp.1105-1113, 2009.

25. J. Li and J. Li "Environmental/economic/reliability Power Dispatch Based on RS and IPSO Approach," in Proc. $6^{\text {th }}$ Int. Conf. on Nat. Comput.-ICNC'10,2010, vol. 8,pp. 3948-3952.

26. G. Krishna and A. Krishna, "Study on Techniques for Combined Economic and Emission Dispatch," Global J. Inc., vol.11, no.5, Jul.2011.

27. T. Niknam, M.R. Narimani, J. Aghaei, and R. Azizipanah-Abarghooee, "Improved particle swarm optimization for multi-objective optimal power flow considering the cost, loss, emission and voltage stability index," IET, Gen., Transm. Distrib. 2012. vol. 6, no. 6, pp. 515-527.

28. R. Hooshmand, M. Parastegari and M. J. Morshed, "Emission, reserve and economic load dispatch problem with non-smooth and non-convex cost functions using the hybrid bacterial foraging-Nelder-Mead algorithm,"Appl. Energy,vol.89,no.1, pp.443-453, 2012.

29. A. Gupta, K. K. Swarnkar, and K. Wadhwani , "Combined Economic Emission Dispatch Problem using Particle Swarm Optimization," Int. J. of Comp. Appl.,vol. 49, no.6, Jul. 2012.

30. F.R. Pazheri, M.F. Othman, N.H.Malik and A.A.Al-Arainy, "Optimization of pollution emission in power dispatch including Renewable energy and energy storage," Res. J. Appl. Sci. Eng. and Tech., vol.4, no.23, pp.5194-5156, 2012.

31. R. V. Rao, V. J. Savsani, and D. P. Vakharia, "Teaching-learning-based optimization: an optimization method for continuous non-linear large scale problems," Information Sciences, vol. 183, no. 1, pp. 1-15, 2012. 
32. F.R. Pazheri and M.F. Othman, "Environmental and Economic Power Dispatch for Hybrid Power System with Distributed Energy Storage," IEEE Symp. Ind. Electron. Appl., pp.117-121, 2013.

33. A.A.EIDesouky, "Security and Stochastic Economic Dispatch of Power System including Wind and Solar Recourses with Environmental Consideration," Int. J. Renew. Energy Res., vol.3, no.4, 2013.

34. R.gopalakrishnan and A. krishnan, "An efficient technique to solve combined economic and emission dispatch problem using Modified Ant colony optimization," Indian Academy of Sciences, vol. 38, pp. 545-556, Aug2013.

35. N. A. Khan, Ahmed, B. Awan and A. Mahmood, "Combined emission economic dispatch of power system including solar photo voltaic generation,” Energy Convers. Manag. vol. 92, pp.82-91, 2015.

\section{AUTHORS PROFILE}

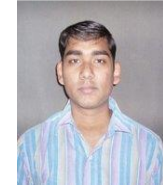

Rajanish kumar kaushal, is born in 1986. He graduated from Madan Mohan Malviya Engineering College Gorakhpur, in Electrical engineering in

2009. He completed his Post graduation in Power System from the National institute of Technology Hamirpur in 2011.Presently, Pursuing Ph.D. in Electrical Engineering

Chandigarh. Department of the Punjab Engineering College

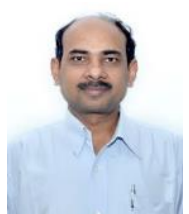

Dr. Tilak Thakur, is born in $1963 . \quad$ He graduated from B.I.T. Sindri, in Electrical engineering in 1987. He completed his Post graduation in Power System from the same institute and achieved his $\mathrm{PhD}$ in Electronic Instrumentation from Indian School of Mines, Dhanbad in the area of SCADA in 1999.

He served as a lecturer in B.I.T., Sindri and NERIST Arunachal Pradesh. Presently, he is Professor in the Department of Electrical Engineering, Punjab Engineering College (PEC), Chandigarh, India. He has a teaching experience of more than 25 years. He is involved in active Research in Power System Automation and Control. 